\title{
Dissolution Testing: A Fast, Efficient Procedure for Degassing Dissolution Medium
}

\section{Intradurtion}

The United States Pharmacopeia (USP) (1) recognizes that dissolved gases in the dissolution medium may affect the dissolution test results and recommends that the gases be removed before the test is performed. The USP suggests heating the medium, with gentle stirring, to $45^{\circ} \mathrm{C}$ and then filtering it under vacuum through a filter having $0.45 \mu \mathrm{m}$ or less porosity. The filtered medium is stirred vigorously during filtration and for 5 minutes under vacuum after filtration is completed. Other degassing procedures may be used, provided they are validated.

Test results for some drug formulations are not affected by dissolved gases. Other formulations are highly sensitive to dissolved gases in the dissolution medium. Dissolution media with different levels of dissolved gases must be used to determine if test results are affected by dissolved gases. Because the dissolved gases can never be completely removed, the test must be performed at ever decreasing levels until repeatable test results are obtained. To test each formulation in this fashion would be very time consuming.

Because of the large volume of dissolution medium required in the test, it is awkward and tedious to use the degassing procedure suggested by the USP. Is such a procedure adequate for all drug formulations? How can an alternative procedure be validated? To answer these questions the availability of a drug formulation that is highly sensitive to dissolved gases would be most helpful. The formulation could be used to establish the level of dissolved gases that does not affect dissolution test results. The formulation could also be used to compare alternative degassing procedures.

Since 1979, the FDA Division of Drug Analysis (DDA) has been using in-house calibrator tablets, called NCDA\#2, which are extremely sensitive to dissolved gases in the dissolution medium (2-4). They were originally available commercially but are no longer on the market. NCDA\#2 tablets are 10-mg prednisone tablets which are tested with the paddle at $50 \mathrm{rpm}$ in $500 \mathrm{~mL}$ of degassed water for 30 minutes.
The USP has two types of calibrator tablets. The USP Prednisone Calibrator Tablets are not affected by dissolved gases in the medium with the paddle method. They are very much affected when the basket method is used at $50 \mathrm{rpm}$ and somewhat affected at $100 \mathrm{rpm}$ with the basket. The USP Salicylic Acid Calibrator Tablets show little sensitivity to dissolved gases with the basket method and at $50 \mathrm{rpm}$ with the paddle. They are somewhat affected with the paddle method at $100 \mathrm{rpm}$ (3). Thus, in validating degassing techniques with the USP Calibrator Tablets, useful results should be expected only when the prednisone tablets are tested with the basket at $50 \mathrm{rpm}$.

Since 1981 we have used a degassing procedure that is as effective as the USP procedure (3). This procedure degasses 18 liters of medium in 15 minutes. We generally use the degassed medium on the same day, but it can be used the next day if it is left in stoppered volumetric flasks. This paper shows the ruggedness of the procedure when these conditions are varied. The NCDA\#2 in-house calibrator was used to monitor the effect of the level of the dissolved gases in the dissolution medium. When the medium is supersaturated with air, it is possible to obtain dissolution results of $60-70 \%$ of label claim with the paddle at $50 \mathrm{rpm}$ in 500 $\mathrm{mL}$ of water. When the air content is lowered to the point that the test results are no longer affected, the results are in the range of $29-35 \%$.

\section{Experimental Conditions}

\section{Reagents}

Water, purified by being pumped through a reverse-osmosis system and then through an ionexchange cylinder under pressure, was used for all tests.

\section{Apparatus}

A Distek (Model 2100A) Dissolution Apparatus was used with a Hewlett-Packard (HP) Multi-Bath Dissolution Testing System. The automated sampling system was equipped with a HP $8452 \mathrm{~A}$ 


\section{Degassing Dissolution Medium. .. e cont.}

Diode-Array spectrophotometer. Distek sampling probes were left in the vessels throughout the test. The vessels provided by Distek were centered with a Distek CenterChek tool at the 400mL mark.
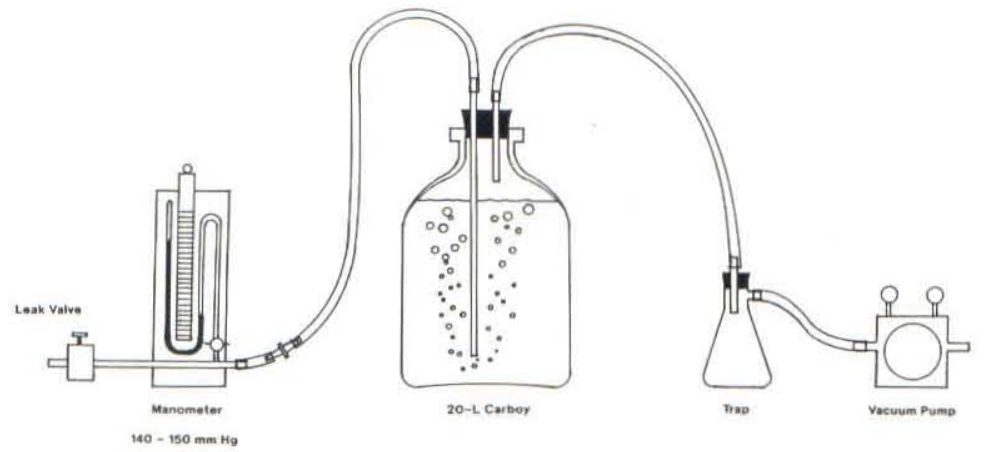

Figure 1 - Division of Drug Analysis Degassing Procedure

\section{Methods and Results}

\section{Effects of Degassing Times}

Six tablets were tested with nondegassed medium. Additional sets of 6 tablets were then tested with water that was degassed for the following lengths of time: 2, 5, 10, 15, 20, and 30 minutes. These tests were all conducted on the same day. After each degassing time the water was siphoned into TD/TC 500-mL volumetric flasks; the water remaining in the carboy was discarded, the carboy was refilled, and the water was degassed again. The next day this testing was repeated on additional sets of six tablets. Table 1 shows that in 5 minutes the medium was thoroughly degassed.

\section{DDA Degassing Procedure}

Refer to Figure 1. Fill a 5-gallon glass carboy with the desired volume of dissolution medium at room temperature. [Caution: the carboy should be either taped or commercially coated to prevent injury should it implode under vacuum.] Fit the carboy with a two-hole rubber stopper. Insert a short glass tube of nominal 9-mm OD through one hole. Insert a longer 9-mm OD glass tube through the other hole so that the end of the tube is less than $1 \mathrm{~cm}$ from the bottom of the carboy. Two lengths of tubing joined by a flexible connection near the stopper may be substituted for the long tube. Connect the short tube to a filter-flask trap and utility electric vacuum pump. Connect the long tube to a closedtube manometer capable of measuring pressures in the range $0-150 \mathrm{~mm} \mathrm{Hg}$. The manometer should also be equipped with an adjustable small leak. (In practice a soft rubber tube and thumbscrew pinch clamp will serve, although a needle valve could also be used.) Reduce the pressure inside the carboy to $140-150 \mathrm{~mm}$ of $\mathrm{Hg}$ (according to the manometer) by closing off the leak. Equilibrate the medium by bubbling air through it at this pressure for a minimum of 15 minutes. Loosen the stopper or otherwise vent the vessel to atmospheric pressure and shut off the pump. Note that the long tube can be conveniently used as a siphon for the degassed liquid.

\section{Table 1}

NCDA\#2 Calibrator Tahlets: Paddle; 50 rpm; 500 ml Conditions

Nondegassed Avg. of 12a Rangea

Degassed 2 minutes

Degassed 5 minutes

Degassed 10 minutes

Degassed 15 minutes

Degassed 20 minutes

Degassed 30 minutes

56.3

35.1

33.4

50.2-61.4

$S D^{b}$

32.8-38.1

29.7-38.3

29.1-34.5

30.7-37.1

$30.1-33.7$

$30.8-36.6$

2.9

1.3

2.1

1.5

1.5
1.7

1.0

1.6

RSD
5.1
3.7
6.3
4.6
5.3
3.3
4.8

\section{Effects of Medium Equilibration}

In Test \#1 18 liters of water in each of two carboys were degassed for 20 minutes. Two sets of six tablets each were immediately tested. Six hours later two additional sets of six tablets each were tested, and twelve 500-mL TD/TC volumetric flasks were filled to the TD mark and stoppered. The next day 12 tablets were tested with the degassed water stored overnight in the stoppered volumetric flasks; an additional 12 tablets were tested with the degassed water stored overnight in the carboy that had been left stoppered with one glass tube vented to the atmosphere.

apercent of label.

'Standard deviation, percent of label.

cRelative standard deviation, percent. 
Table 2 shows that once the medium is degassed, it can be either left in the carboy or placed in glass-stoppered flasks and used the next day.

\begin{tabular}{|c|c|c|c|c|}
\hline \multicolumn{5}{|c|}{$\begin{array}{l}\text { Table } 2 \\
\text { NCDA\#2 Calibrator Tablets: Paddle; } 50 \text { rpm; } 500 \text { ml. }\end{array}$} \\
\hline Conditions & Avg. of $12^{a}$ & Range ${ }^{a}$ & $\mathbf{S D}^{\mathrm{b}}$ & RSDe \\
\hline Tested immediately after degassing & g 33.0 & $30.3-39.4$ & 2.4 & 7.1 \\
\hline Tested 6 hours after degassing & 31.6 & 29.3-34.2 & 1.5 & 4.8 \\
\hline Tested 24 hours after degassing & 33.2 & $31.0-36.8$ & 1.7 & 5.1 \\
\hline $\begin{array}{l}\text { Placed in volumetric flasks } 6 \text { hours } \\
\text { after degassing and tested } 18 \text { hours } \\
\text { thereafter }\end{array}$ & 32.4 & $29.9-36.8$ & 1.8 & 5.5 \\
\hline
\end{tabular}

In Test \#2 12 tablets were tested with nondegassed water. On the same day 18 liters of water in each of two carboys were degassed for 20 minutes, and 12 tablets were tested. The degassed water was left in the stoppered carboys vented to air by the one glass tube. Twelve additional tablets were tested with this water every day for the next 4 days. Six tablets were tested on the seventh day.

Table 3 shows that once the water is degassed, it can be left in the carboy, vented to air with one glass tube, for at least 3 days without absorbing a significant amount of air. By the fourth day the water has absorbed enough air to have a small effect on the results. By the seventh day the water has absorbed so much air that it can no longer be used.

\begin{tabular}{|c|c|c|c|c|}
\hline Conditions & Avg. of $12^{a}$ & Range & $\mathbf{S D}^{\mathrm{b}}$ & RSD \\
\hline Nondegassed & 52.5 & $48.1-56.3$ & 2.3 & 4.4 \\
\hline Tested immediately after degassing & lg 34.7 & 30.437 .0 & 2.5 & 7.2 \\
\hline Tested 1 day after degassing & 32.6 & $29.5-37.2$ & 2.1 & 6.5 \\
\hline Tested 2 days after degassing & 34.8 & $31.1-39.0$ & 2.6 & 7.5 \\
\hline Tested 3 days after degassing & 33.4 & $30.2-35.5$ & 1.5 & 4.6 \\
\hline Tested 4 days after degassing & 35.6 & $32.6-38.7$ & 2.0 & 5.5 \\
\hline Tested 7 days after degassing & $44.4^{d}$ & $42.6-45.6$ & 1.1 & 2.5 \\
\hline
\end{tabular}

apercent of label.

¿Standard deviation, percent of label.

cRelative standard deviation, percent.

aSix tablets tested.

\section{Conclusions}

This degassing procedure is fast and efficient. In 15 minutes, 18 liters of any dissolution medium can be thoroughly degassed. If a surfactant is being used in the medium, the medium must first be degassed without the surfactant for $15 \mathrm{~min}$ utes; then the surfactant is added to the carboy with gentle stirring by a magnetic stirrer until it has dissolved.

As a standard operating procedure at DDA our medium is degassed daily for a minimum of 15 minutes. If the degassed medium is siphoned into glass-stoppered TD/TC volumetric flasks, it can be used the following day. Either the volumetric flasks containing the degassed medium can be placed in a holding tank previously heated to $38^{\circ} \mathrm{C}$ or the medium can be decanted into the dissolution vessels and the temperature of the medium allowed to reach $37 \mathrm{C}$.

It is highly recommended that all laboratories use this degassing technique.

\section{Acknowledgments}

The assistance of Don Cox in the design of this study is gratefully acknowledged.

\section{References}

1. USP 23/NF 18; United States Pharmacopeial Convention: Rockville, MD, 1994; p. 1792.

2. D. C. Cox, W. B. Furman, D. P. Page, J. Pharm. Sci., 72 (9), 1061-1064 (1983).

3. T. W. Moore, J. F. Hamilton, C. M. Kerner, Pharm. Forum, 21 (5), 1387-1396 (1995).

4. T. Moore, R. Shangraw, Y. Habib, Pharm. Forum, 22 (3), Stimuli to the Revision Process (1996). 